\title{
Intra-Uterine Proximal Loop Volvolus in Association with Ileal Atresia: A Pointer to Possible Aetiology of Small Bowel Atresias
}

\author{
Mohammad Aminu Mohammad ${ }^{1,2 *}$, Anyanwu Lofty-John Chukwuemeka ${ }^{1,2}$ \\ ${ }^{1}$ Department of Surgery, Bayero University, Kano, Nigeria \\ ${ }^{2}$ Department of Surgery, Aminu Kano Teaching Hospital Kano, Kano, Nigeria \\ Email: *mohammadsurgery@yahoo.com
}

How to cite this paper: Mohammad, M.A. and Chukwuemeka, A.L.-J. (2016) Intra-Uterine Proximal Loop Volvolus in Association with Ileal Atresia: A Pointer to Possible Aetiology of Small Bowel Atresias. Open Journal of Pediatrics, 6, 213-218.

http://dx.doi.org/10.4236/ojped.2016.63030

Received: June 30, 2016

Accepted: August 12, 2016

Published: August 15, 2016

Copyright $\odot 2016$ by authors and Scientific Research Publishing Inc. This work is licensed under the Creative Commons Attribution International License (CC BY 4.0).

http://creativecommons.org/licenses/by/4.0/

\begin{abstract}
Intrauterine diagnosis of small intestinal volvulus is extremely rare; a small bowel volvulus may be caused, by an atresia or malrotation, and it can also be an etiology for intestinal atresia. Early antenatal diagnosis of fetal intestinal volvulus is difficult. Care full and meticulous prenatal radiological investigations in the experience hand may suggest the diagnosis. We present a male child who presented 9 hours after birth with gangrenous proximal dilated loop volvulus in a type III B intestinal atresia diagnosed intraoperative and was treated successfully. Presence of focal abdominal wall edema in a newborn with intestinal obstruction may suggest this diagnosis.
\end{abstract}

\section{Keywords}

Intra-Uterine, Volvulus, Atresia, Outcome

\section{Introduction}

Intrauterine diagnosis of small intestinal volvulus is extremely rare; a small bowel volvulus may be caused, by an atresia or malrotation, and it can also be an etiology for intestinal atresia [1]. Early antenatal diagnosis of fetal intestinal volvulus is difficult. Care full and meticulous prenatal radiological investigations in the experience hand may suggest the diagnosis; however it may not be able to completely rule out other causes [2]. Our patient was successfully managed for volvulus in the proximal bowel with ileal atresia, in which many series have reported dismal outcome. 


\section{Case Report}

Baby AY, is a full term, male, neonate that was admitted at 9 hours after birth, weighing $2.8 \mathrm{Kg}$ with features of neonatal intestinal obstruction. Typically gross abdominal distention, copious bilious vomiting which later became feculent, was yet to pass meconium and a focal anterior abdominal wall edema. There were no features of peritonitis and or that of bowel perforation. There were no predisposing factors to necrotizing enterocolitis. Examination showed dehydrated but stable newborn with fresh umbilical stump, visible bowel marking and central abdominal wall pitting edema. Ano-rectal examination revealed tight rectum with sticky brownish jelly string of mucous seen.

He was resuscitated with intravenous $4.3 \%$ dextrose in 0.18 saline, $50 \mathrm{mg} / \mathrm{Kg}$ ceftaxidime and $7.5 \mathrm{mg} / \mathrm{Kg}$ metronidazole and intra venous vitamin $\mathrm{K}$. Plain abdominal $\mathrm{X}$-ray revealed dilated bowel with multiple air fluid level (Figure 1).

Complete blood count and blood urea and electrolyte are within normal range. Blood was also grouped and cross matched.

At laparotomy serous fluid was drained and a dilated gangrenous but intact proximal dilated loop of ileum was delivered and 720 degrees of volvulus $10 \mathrm{~cm}$ from the terminal end of atretic ileum in a close loop obstruction was noted (Figures 2-4).

Resection of the close loop bulbous part with the volvulus insitu and end to end anastomosis. The patient had uneventful recovery with no complication 2 years after (Figure 5). Consent to publish this case report was obtained from the parents, which was gladly given to promote medical knowledge.

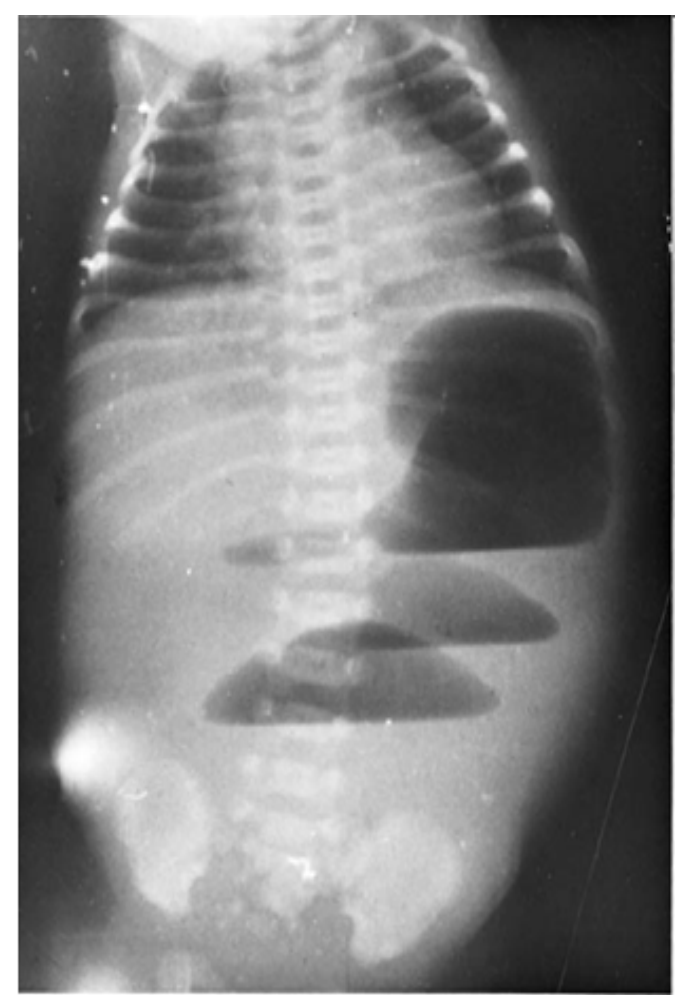

Figure 1. Showed multiple air-fluid interphases. 


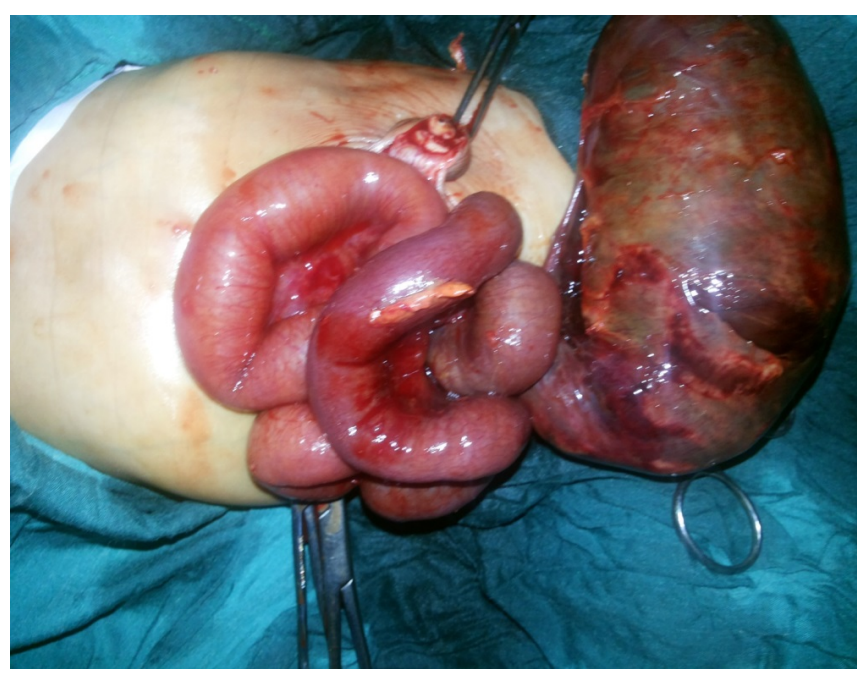

Figure 2. Close loop obstruction of the terminal proximal bowel.

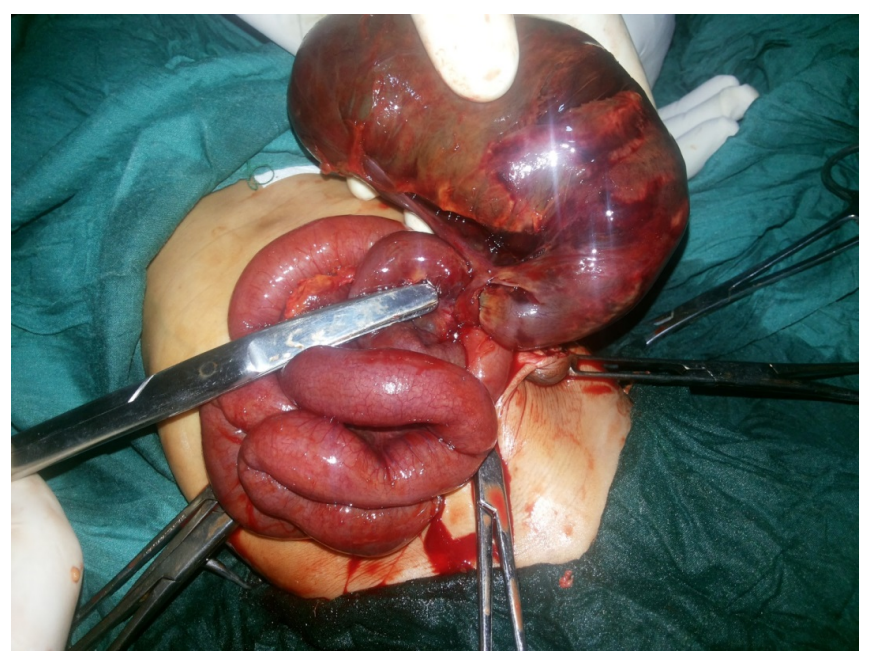

Figure 3. Showing the level of the volvulus.

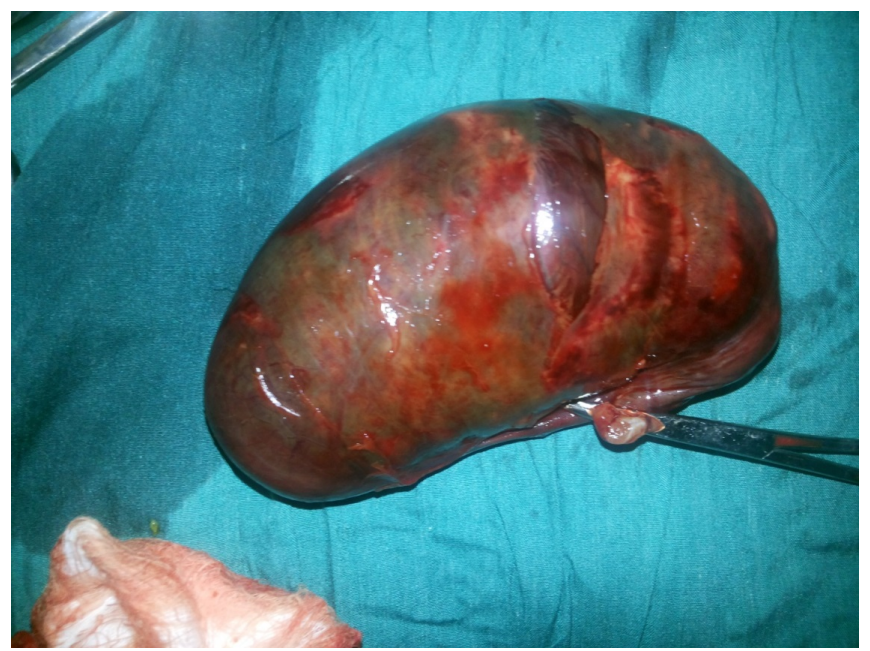

Figure 4. Showing the resected terminal dilated proximal ileum. 


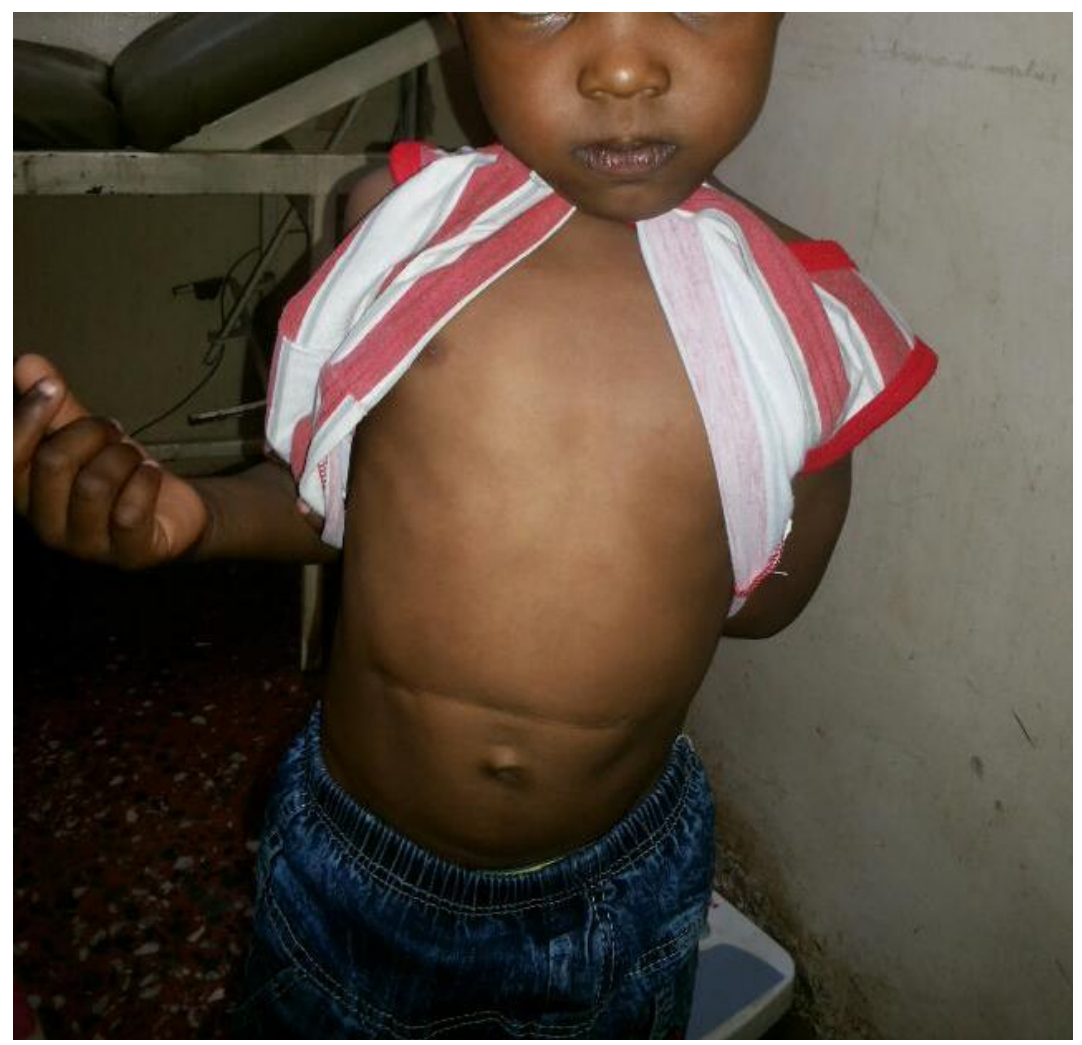

Figure 5. Showing the child at the age of 2 years having normal growth and development.

\section{Discussion}

Intrauterine diagnosis of small intestinal volvulus is extremely rare; a small bowel volvulus may be caused, by an atresia or malrotation, and it can also be an etiology for intestinal atresia [1]. Early antenatal diagnosis of fetal intestinal volvulus is difficult because symptoms and signs in pregnant woman are non-specific and not easily demonstrated [2]. Intrauterine volvulus and intussusception were commonly observed in single mid- and low Jejuno-Ileal Atresia. Volvulus may not only cause Jejuno-Ileal Atresia but can also results from anatomic changes after the development of the atresia in some cases [3]. Intestinal mesenteric abnormalities as a cause of intestinal atresia unifies under one etiology all the lesions observed in intestinal atresia. Although this theory does not rule out other causes of intestinal atresia, intestinal mesenteric defects may be the primary condition under which intestinal atresia occurs [4].

Jejuno-Ileal Atresias (JIA) account for about one third of cases of all neonatal intestinal obstructions and It is well known that an intrauterine mesenteric vascular accident in the third trimester as a major cause [1]-[3]. Segmental volvulus is the third major etic-pathology of this anomaly after intussusception and intestinal perforation, followed by malrotation, internal hernia or thromboembolism [1]. volvulus like other intrauterine mesenteric vascular insults, primary segmental volvulus can also cause vascular insufficiency and lead to ileal atresia as in our patient. It has been postulated that if these children were to be born at term they would have presented with ileal atresia 
[4]-[7]. It is extremely difficult to predict the time of volvulus and prognosis of the affected fetus owing to a wide range of presentation and course: from preterm to term, from fetal demise to survivor with good outcome [2]. It may be one of the causes of late intra uterine fetal death and or premature delivery. Care full and meticulous prenatal radiological investigations in the experience hand may suggest the diagnosis, however may not be able to completely rule out other causes, such as intussusception and internal hernias [3]. Our index case presented with classical features small bowel obstruction and softie features of peritonitis within few hours of birth, which point to the fact that the volvulus of the proximal terminal part of the atresia must have occurred prenatally. To buttress this point is the presence of gangrenous bowel within a short period of time.

Presence of generalized abdominal wall edema in the neonatal usually suggests peritonitis and or bowel perforation. This patient presented with focal central abdominal wall which may suggest point of contact between the inflamed bowel and anterior abdominal wall. In our patient there was no bowel perforation, however the peritonitis might have results from translocation of organisms due to the increasing tension from the close loop obstruction. Saline et al. in a ten year period had 65 patients with Jejuno-ileal atresia of which 11 (16.9\%) of them were found to have associated volvulus intra-operatively which is less than one case per year [1]. All their patients presented with of bilious vomiting and abdominal distension after birth as it is similar with our patient. There are three types of volvulus associated with intestinal atresia according to Komuro et al, type 1, involving the proximal end as opposed to the distal end; type 2, involving only the distal end; and type 3, located between the proximal and distal blind end [3].

Our patient belongs to the type 1 category as in the majority of cases of such association. These suggested that not only does intra-uterine volvulus cause small bowel atresia secondary to ischemic necrosis of bowel; the reverse may also be true [3]. The hugely dilated blind ending proximal bowel along with contraction of the mesenteric defect and increased peristalsis of the proximal bowel may lead to volvulus of the proximal atresia. Shalini observed that the mortality $(90.1 \%$ vs $31.5 \%)$ and morbidity $(71.4 \%$ vs 22.4\%) was significantly higher in the Jejuno-ileal atresia associated with volvulus when compared to those without volvulus was proved to be statistically significant [1]. Our patient had uneventful recovery and has no long term complication and an unimpeded growth.

\section{Conclusion}

Intrauterine diagnosis of small intestinal volvulus is extremely rare; a small bowel volvulus may be caused, by an atresia or malrotation, and it can also be an etiology for intestinal atresia. Copious bilious vomiting few hours after birth, presence of focal anterior abdominal wall edema, may suggest complicated neonatal intestinal obstruction. High index of suspicion, meticulous resuscitation and early surgical intervention may influence the outcome. 


\section{References}

[1] Sinha, S. and Sarin, Y.K. (2012) Outcome of Jejuno-Ileal Atresia Associated with Intraoperative Finding of Volvulus of Small Bowel. Journal of Neonatal Surgery, 1, 37.

[2] Chung, J.H., Lim, G.-Y. and Wec, S. (2013) Fetal Primary Small Bowel Volvulus in a Child without Intestinal Malrotation . Journal of Pediatric Surgery, 48, E1-E5. http://dx.doi.org/10.1016/j.jpedsurg.2013.05.011

[3] Komuro, H., Hori, T., Amagai, T., Hirai, M., Yotsumoto, K., Urita, Y., et al. (2004) The Etiologic Role of Intrauterine Volvulus and Intussusception in Jejunoileal Atresia. Journal of Pediatric Surgery, 39, 1812-1814. http://dx.doi.org/10.1016/j.jpedsurg.2004.08.037

[4] Black, P.R., Mueller, D., Crow, J., Morris, R.C. and Husain, A.N. (1994) Mesenteric Defects as a Cause of Intestinal Volvulus without Malrotation and as the Possible Primary Etiology of Intestinal Atresia. Journal of Pediatric Surgery, 29, 1339-1343. http://dx.doi.org/10.1016/0022-3468(94)90111-2

[5] Shankar, R., Rao, S. and Shetty, K.B. (2013) Primary Segmental Volvulus Mimicking Ileal Atresia. Journal of Neonatal Surgery, 2, 6.

[6] Jung, E., Choi, S.O. and Park, W.H. (2011) Primary Segmental Volvulus of the Ileum Mimicking Meconium Plug Syndrome. Journal of the Korean Surgical Society, 80, 85-87. http://dx.doi.org/10.4174/jkss.2011.80.Suppl1.S85

[7] Hong, J. (1997) Ileal Atresia Due to Intrauterine Intussusception. Journal of the Korean Surgical Society, 52, 732-737.

\section{Submit or recommend next manuscript to SCIRP and we will provide best service} for you:

Accepting pre-submission inquiries through Email, Facebook, LinkedIn, Twitter, etc. A wide selection of journals (inclusive of 9 subjects, more than 200 journals)

Providing 24-hour high-quality service

User-friendly online submission system

Fair and swift peer-review system

Efficient typesetting and proofreading procedure

Display of the result of downloads and visits, as well as the number of cited articles

Maximum dissemination of your research work

Submit your manuscript at: http://papersubmission.scirp.org/ 